\title{
Capacity-oriented curriculum system of optoelectronics in the context of large category cultivation
}

Yuan Luo, Zhangfang Hu, Yi Zhang

Yuan Luo, Zhangfang Hu, Yi Zhang, "Capacity-oriented curriculum system of optoelectronics in the context of large category cultivation," Proc. SPIE 10452, 14th Conference on Education and Training in Optics and Photonics: ETOP 2017, 104524U (16 August 2017); doi: 10.1117/12.2269290

SPIE Event: 14th Conference on Education and Training in Optics and Photonics, ETOP 2017, 2017, Hangzhou, China 


\title{
Capacity-oriented curriculum system of optoelectronics in the context of large category cultivation
}

\author{
Yuan Luo*, Zhangfang Hu, Yi Zhang \\ School of Electronic Engineering, Chongqing University of Posts and Telecommunications, \\ Chongqing, China, 40065
}

\begin{abstract}
In order to cultivate the innovative talents with the comprehensive development to meet the talents demand for development of economic society, Chongqing University of Posts and Telecommunications implements cultivation based on broadening basic education and enrolment in large category of general education. Optoelectronic information science and engineering major belongs to the electronic engineering category. The " $2+2$ " mode is utilized for personnel training, where students are without major in the first and second year and assigned to a major within the major categories in the end of the second year. In the context of the comprehensive cultivation, for the changes in the demand for professionals in the global competitive environment with the currently rapid development, especially the demand for the professional engineering technology personnel suitable to industry and development of local economic society, the concept of CDIO engineering ability cultivation is used for reference. Thus the curriculum system for the three-node structure optoelectronic information science and engineering major is proposed, which attaches great importance to engineering practice and innovation cultivation under the background of the comprehensive cultivation. The conformity between the curriculum system and the personnel training objectives is guaranteed effectively, and the consistency between the teaching philosophy and the teaching behavior is enhanced. Therefore, the idea of major construction is clear with specific characteristics.
\end{abstract}

Keywords: CDIO,Capacity-oriented curriculum system, Opto-Electronic Engineering, large category cultivation

\section{INTRODUCTION}

With the rapid development of economic society, the innovation training system of optoelectronic information science and engineering major, which regards the cultivation of students' engineering ability and innovation ability as the core and meets the needs of the market diversification, is explored and established, and it is implemented through the construction of specific courses and curriculum group. This problem must be faced and urgently solved.

Optoelectronic information science and engineering major began enrollment from 2000, which has more titles, such as Chongqing third-specialty major, Chongqing specialty major, the first batch of school-level brand major and professional promotion program project major of Chongqing University of Posts and Telecommunications and so on. In addition, it is the information advantage major in Chongqing University of Posts and Telecommunications.

Optoelectronic information science and engineering major belongs to the electronic engineering category. The "2+2" mode is utilized for personnel training, where students are without major in the first and second year and assigned to a major within the major categories in the end of the second year. In the context of the comprehensive cultivation, in order to adapt to the demand for the professional engineering technology personnel suitable to industry and development of local economic society, the concept of CDIO engineering ability cultivation is used for reference. Thus the curriculum system for the three-node structure optoelectronic information science and engineering major is proposed, which attaches great importance to engineering practice and innovation cultivation under the background of the comprehensive cultivation. The conformity between the curriculum system and the personnel training objectives is guaranteed effectively, and the consistency between the teaching philosophy and the teaching behavior is enhanced. Therefore, the idea of major construction is clear with specific characteristics.

*luoyuan@cqupt.edu.cn; phone 8623 6246-0513; fax 8623 6246-1719; cqupt.edu.cn

14th Conference on Education and Training in Optics and Photonics: ETOP 2017, edited by Xu Liu,

Xi-Cheng Zhang, Proc. of SPIE Vol. 10452, 104524U · @ 2017 ICO, IEEE, OSA, SPIE

CCC code: $0277-786 X / 17 / \$ 18 \cdot$ doi: $10.1117 / 12.2269290$

Proc. of SPIE Vol. $10452104524 \mathrm{U}-1$ 


\section{THE CAPACITY-ORIENTED CURRICULUM SYSTEM FOR THE THREE-NODE STRUCTURE OPTOELECTRONIC MAJOR IN THE BACKGROUND OF THE LARGE CATEGORY CULTIVATION}

Under the background of the large category cultivation, the curriculum system of optoelectronic information science and engineering major which emphasizes on the engineering practice ability and innovative training is of great significance. The system diagram like fishbone is shown as figure 1.

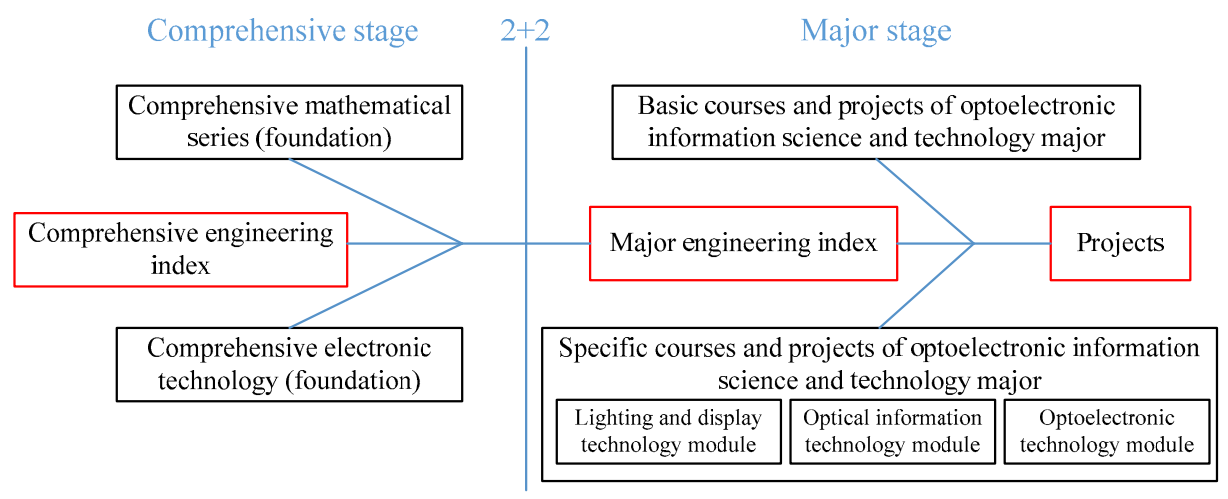

Figure 1. The fishbone diagram of photoelectric information science and engineering course system

From the figure, we can clearly see that the spindle of key ability cultivation in this major are constituted of large categories, major engineering guidance and engineering projects together. Unlike the two-point structure of the primary guide project and the engineering project of the regular CDIO system, as a result of the large categories training, we add a major engineering guidance in this system. Thus a three-point structure are constituted. Students' engineering ability and innovation concept are strengthen through different forms and courses in three important training node of admission, major diversion and graduation. The initial point in the three-point structure is at the beginning of freshmen enrollment. Through the series of freshmen guidance and base practice project, the concept for the engineering target of the comprehensive cultivation is established; the central point in the three-point structure is between second semester of the second grade and in the first semester of third grade. In the second semester of second grade, the subject basic introductory course are set up. In addition, at the end of the second grade, the major engineering guidance is completed through the major diversion seminar to strengthen students' engineering concept. So completion of the diversion is the primary guarantee for the individual's development needs. The first semester of third grade is a major training stage. Through the cutting-edge technology courses in the field of optoelectronics, the further guidance of the major's engineering research is established. After the accomplishment of the courses, the major diversion seminar and major laboratory visits are arranged to perform the major diversion. The guarantee of students' personality development needs is strengthened further. The end of the three-point structure is the fourth grade where students mainly perform the graduation practice and graduation design. By the training from the relevant courses and experimental projects, students can use the knowledge to implement professional subjects with a certain difficulty. They can further learn and apply the professional knowledge from the perspective of solving the project, and preliminarily master engineering thinking method.

In the period of the comprehensive cultivation, students mainly study courses in mathematics and electronics with the relevant experiment courses, which can solve the problem for both the basic mathematical and electronic tools and the initial application of the tools. In the processes of studying majors, through studying the series of major core curriculum, major direction courses and comprehensive innovative projects, student can use the basic tools, such as mathematics, electrical and electronic and so on, to improve the ability of engineering and innovation. The offered practical modules of the major basis and major field are equivalent to the secondary project in the CDIO model. Due to the use of modular practice, there is no experimental session of the corresponding course, so the comprehensive practice links involved in multiple courses are arranged, effectively strengthening students' ability of solving engineering problem and innovative practice. For example, the experimental module of the optical information in the major basic integrates many courses knowledge such as information optics, optical information processing, MATLAB and photoelectric image processing and so on. The practice materials compiled and used by us can also clearly reveal the ideas of the comprehensiveness and 
designability, such as "Information Optical Experiment Course" contains these content and the corresponding experimental skill training guidance, and the course also establish the video experimental guidance to ensure students' study and application.

\section{HIERARCHICAL CORE CURRICULUM ORGANIZATION SYSTEM}

The curriculum group is the integration in the various disciplines, which is the structure formed through the competition and cooperation between the elements in the university curriculum system, so curriculum construction is a systematic project. This curriculum is based on the four-level curriculum system considering the understanding order of the human culture as the main body, including the liberal arts course curriculum, general course group, major basic course group and major course group. According to the relationship in the category, major and major field, by emphasizing the discipline major characteristics and the accurately positioning the "recent development zone", the curriculum group can be formed. For this purpose, the organization way focusing on the course's relevance which is vertical stratification and horizontal groups is adopted, highlighting the subject knowledge, professional basis, the vertical relationship between the major courses and the progressive relationship of the ability level. The organization of the core curriculum is shown in figure 2 .

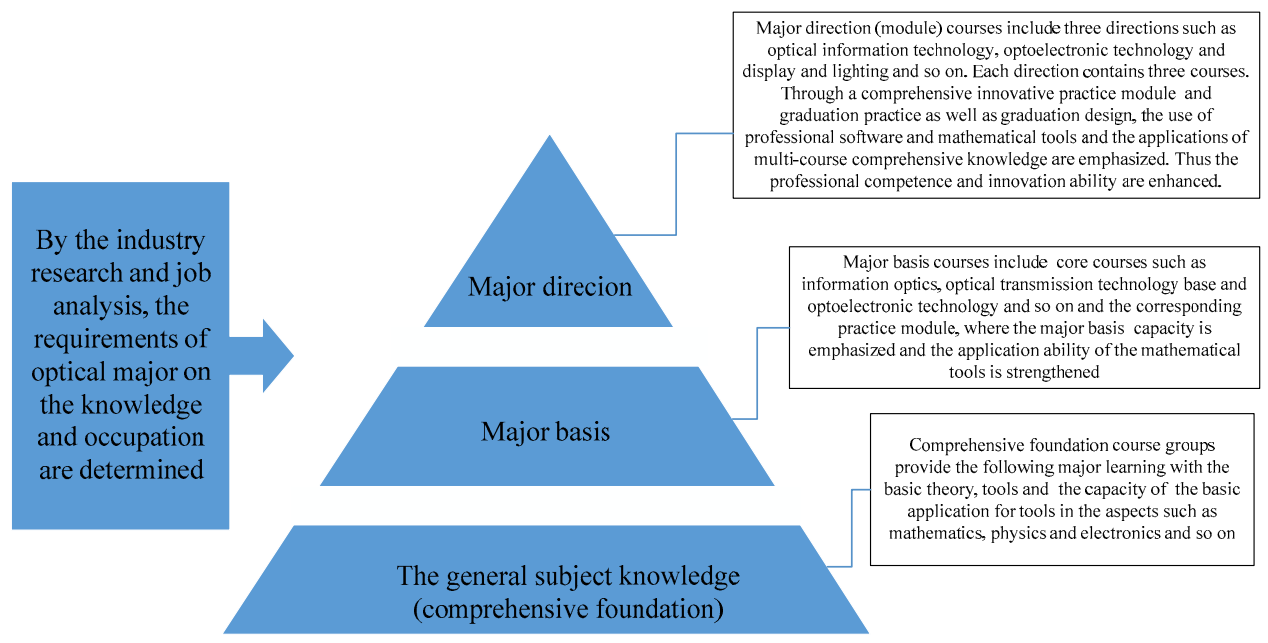

Figure 2. The organization of the core curriculum

The core course group of electronic engineering major mainly corresponds to the three levels of subject knowledge (public foundation), major foundation and major courses, emphasizing the cultivation of three abilities respectively. At the level of the general subject knowledge, through these methods such as the combination of courses and matches, the ability of mathematical infrastructure, electronic circuit analysis and a certain application ability for mathematical and electronic tools are emphasized; in the major basis, through the experiment and practice, students' application capacity for the major basic knowledge is promoted; in the major curriculum, through the experiment module with the comprehensive and innovative as well as projects such as graduation practice and graduation design and so on, both combining production with research and combining science with education can further promote students' engineering ability and innovation ability. The combination of three competencies strengthens the connection between vertical courses and takes into account the interaction, association and radiation between the core curriculum and other courses.

\section{THE INNOVATIVE TALENT TRAINING MODEL DRIVEN BY THE STRONG DISCIPLINE FOR THE INDUSTRIAL DEVELOPMENT}

By studying the relationship between major construction and industry and between major construction and discipline development, the innovative talent training mode driven by the strong discipline for industrial development is put forward. The school of optoelectronic Engineering has two first class disciplines of electronic science and technology 
and optical engineering. The electronic science and technology is not only the Chongqing 12th five-year key disciplines but also the key disciplines which will be used to apply for PhD. Through a series of survey, research and expert consultation, combining with the school teaching institutions to adjust the constructed guiding ideology, the photoelectric information science and engineering major is utilized to support the development of physical electronics secondary disciplines such as optical engineering disciplines and electronic science and technology. In the supported field of the overall discipline planning at school, optoelectronic technology and application direction in the electronic science and technology and optical engineering such as optical communication and photoelectric sensing system, micro-nano devices and systems and photoelectric detection technology and so on are focused on develop. To this end, the three directions modular curriculum group for the optoelectronic technology, optical information technology and display and lighting technology and so on are identified as the core construction direction in the photoelectric information science and engineering major, and they are determined in the major module of the corresponding training program.

\section{THE KEY IMPLEMENTATION OF TEACHING RESOURCES, TEACHERS TEAM AND THE CONCEPT OF SECURITY AND IDEAS}

(1) On the basis of the photoelectric major experimental platform built by the central government and local government, the platform of scientific research and ability enhancement and the discipline platform, a strong practical environment of the major innovation is built.

On the basis of the existing photoelectric major laboratory, we have obtained four supported projects built by the central government and local government, listed as the electro-optical device and system research platform cooperated the central government with the local government, the key disciplines of electronic science and technology (new lighting and display), the experiment platform of photoelectric information science and engineering and photoelectric new sensor research development platform, whose fund is more than 16 million. The four platforms are contributed to enhancing students' ability with the optoelectronic information science and engineering major. At the same time, through industrystudy-research cooperation, the experimental practice base outside the school can be constructed. Thus a large innovative practice platform which is systematic integrated the subjects resources is formed. The support of the platform for the major characteristic direction module is shown as figure 3.

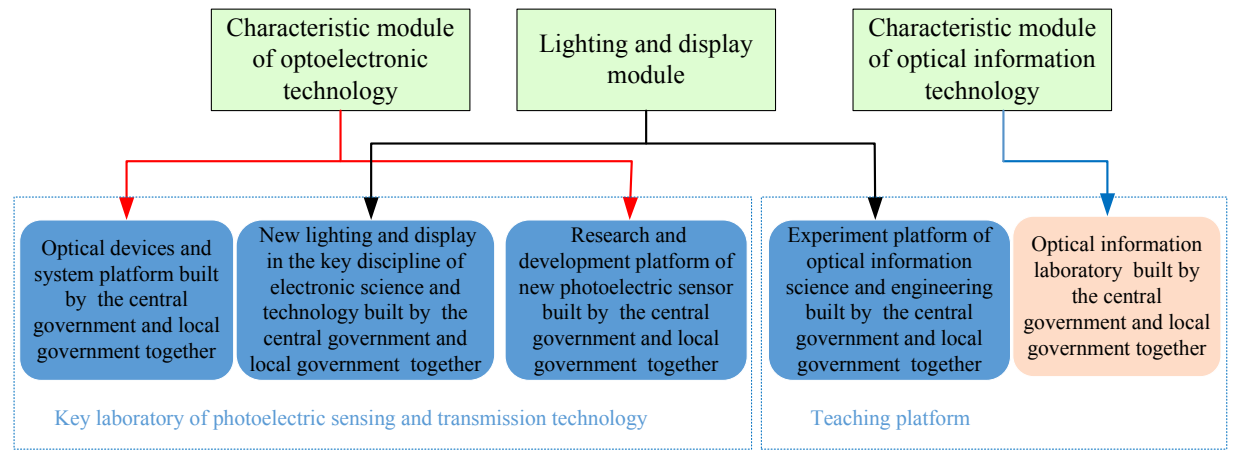

Figure 3. The support of the platform for the major characteristic direction module

In the construction of major basis and major curriculum, focusing on the core curriculum and key courses, teaching materials and teaching resources are constructed to achieve the publishment of the core teaching materials, the full use and the full coverage of site resources construction of key curriculum, creating a very good soft environment for students.

(2) The active construction of professional teacher team

In the talent introduction of teaching team, by means of unity of knowledge and action, teaching others teaching yourself and three combination (curriculum construction, teaching materials construction and discipline construction), the core teachers are both the person responsible for the key courses and the organizer of teaching materials as well as the backbone staffers of related disciplines. They teach and research weekly. In addition, the achievements of teacher evaluation is outstanding and scientific achievement are prominent. Through team cooperation and common development, the curriculum construction and teaching reform can be ensured to develop sustainably. 


\section{CONSTRUCTION EFFECTIVENESS}

This research was supported by the Chongqing high school key teaching reform research project yjg20163003. By the construction, optoelectronic information science and engineering major has successfully become the Chongqing three special major. Four projects built by the central government and local government together accomplish the construction of the practice environment. Nearly 10 teaching reform projects and curriculum construction project have been completed gradually. 7 teaching materials and 2 monograph have been published. 29 educational reform papers have been published. 13 new experiments have been developed. Students have received 21 national awards, 48 provincial awards and 10 college student innovative experimental projects. Undergraduate students have obtained 21 excellent graduation thesis, published 6 papers and applied for 3 national invention patents. The graduation rate and employment rate keep quite high. Thus a great number of talented persons have contributed to the development of society, and the achievements have been affirmed by other colleges.

\section{REFERENCES}

[1] Peihua G, Minfen S, Shengping L, Zhemin Z, Xiaohua L, Guanjing X. "From CDIO to EIP-CDIO: A probe into the mode of talent cultivation in Shantou University," Research in Higher Education of Engineering. Papers (1): 12-20 (2008).

[2] Zhangfang H, Wu P, Yuan L, Yan W. "Reform and practice of innovative talents training mode in optoelectronic information science and engineering major," Scientific Consult (Technology \& Management). Papers (9): 126-127 (2014).

[3] Yan W, Yuan L, Zhangfang H. "The application of professional software in practical teaching of optoelectronic information science and engineering major," Gakuen: Scholar's Spiritual Home. Papers (12): 13-14 (2014).

[4] Yuan L, Yi Zhang, Honggang H. "Teaching team construction of core course group of electronic engineering," Science and Technology of West China. Papers (9): 94-94 (2013).

[5] Yan W, Yuan L, Zhangfang H. "Exploration on opening experiment optical information professionals," Scientific Consult: Technology \& Management. Papers (9): 120-121 (2014). 